\title{
Spiro annulation of cage polycycles via Grignard reaction and ring-closing metathesis as key steps
}

\author{
Sambasivarao Kotha", Mohammad Saifuddin, Rashid Ali and Gaddamedi Sreevani
}

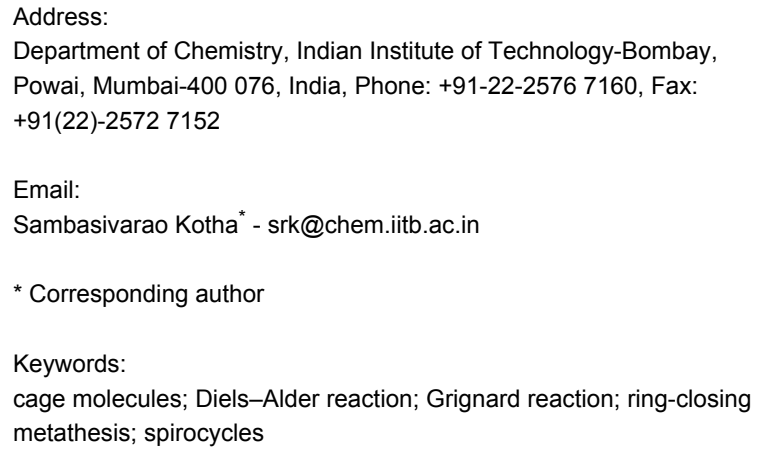

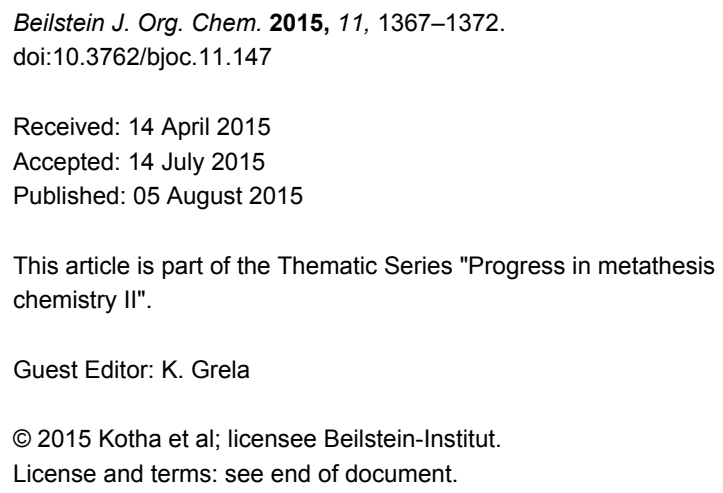

\begin{abstract}
A simple synthetic strategy to $C_{2}$-symmetric bis-spiro-pyrano cage compound 7 involving ring-closing metathesis is reported. The hexacyclic dione $\mathbf{1 0}$ was prepared from simple and readily available starting materials such as 1,4-naphthoquinone and cyclopentadiene. The synthesis of an unprecedented octacyclic cage compound through intramolecular Diels-Alder (DA) reaction as a key step is described. The structures of three new cage compounds 7, 12 and $\mathbf{1 8}$ were confirmed by single crystal X-ray diffraction studies.
\end{abstract}

\section{Introduction}

Design and synthesis of architecturally intricate cage molecules is a worthwhile challenge. The unique properties associated with the carbocyclic cage frameworks are the main reasons for pursuing their synthesis $[1,2]$. They are valuable synthons to assemble natural as well as non-natural products $[3,4]$. In addition, the cage molecules are interesting targets because of their unusual structural features such as the deformation of the ideal $\mathrm{C}-\mathrm{C}$ bond angles, high degree of symmetry and the enhanced ring strain etc. [5-18].

The structures of a variety of intricate cage systems, for example, snoutane (1) [5], pentaprismane (2) [10], dodeca- hedrane (3) [11-19], cage crown ether 4 [20], amantadine (5) and pushpakenediol (6) [21] along with the target molecule 7 are shown in Figure 1. Interestingly the amino group containing cage molecule amantadine (5) exhibits antiviral properties [22].

Although, several methods are available for the construction of cage compounds [7,23-33], the synthesis of symmetrical spirocage molecule 7 seems to be a synthetic challenge due to the proximity of the two carbonyl groups in dione $\mathbf{1 0}$ which provides a hemiketal with various nucleophiles [34-39]. In view of various applications of cage molecules and the documented difficulties in their synthesis, we conceived a short synthetic 


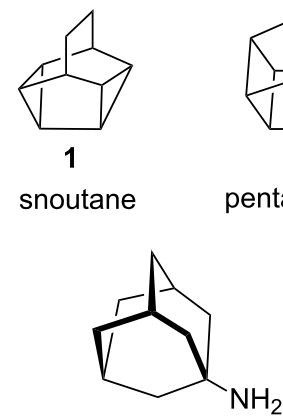

5 amantadine

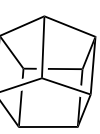

2

entaprismane

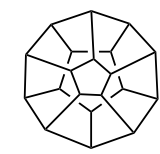

3

dodecahedrane

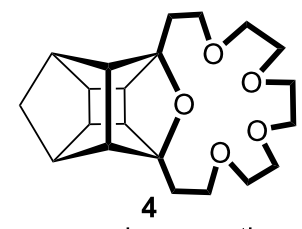

caged crown ether

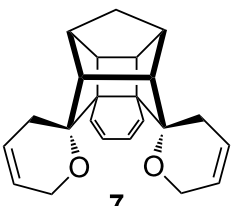

Target structure

Figure 1: Structures of diverse biologically as well as theoretically interesting molecules.

route to $C_{2}$-symmetric bis-spiro-pyrano cage compound 7 . To this end, the Grignard addition and ring-closing metathesis (RCM) are considered as viable options. The retrosynthetic analysis to the target bis-spiro-cage compound 7 is shown in Figure 2. The target compound 7 could be obtained from $O$-allylation of the Grignard addition product $\mathbf{1 1}$ followed by the two-fold RCM sequence. The required cage dione $\mathbf{1 0}$ could be constructed in two steps from readily available starting materials such as 1,4-naphthoquinone (9) and cyclopentadiene (8) $[40,41]$.

\section{Results and Discussion}

In connection with the synthesis of new cage molecules, we reported a new approach to the hexacyclic dione $\mathbf{1 0}$ and related systems via Claisen rearrangement and RCM as key steps $[21,30]$. Here, we have prepared the cage dione $\mathbf{1 0}$ by the known route involving two atom-economic protocols such as Diels-Alder reaction and [2 +2 ] photocycloaddition [42-45] (Scheme 1).

Later, the hexacyclic cage dione $\mathbf{1 0}$ was subjected to a Grignard reaction with comercially available allylmagnesium bromide in diethyl ether. Under these conditions, we realized the formation of hemiketal $\mathbf{1 2}$ in $84.7 \%$ yield instead of the
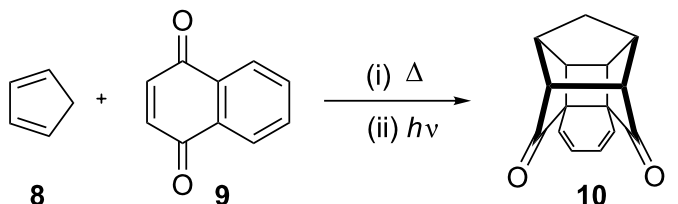

Scheme 1: Synthesis of hexacyclic cage dione 10

expected diallylated product 11 (Scheme 2). In similar fashion, the cage dione 10 was treated with comercially available vinylmagnesium bromide and the hemiketal 13 [46,47] was obtained in $89.2 \%$ yield instead of the desired divinylated compound $\mathbf{1 4}$ (Scheme 2). The proximity of the carbonyl groups may be responsible for the formation of hemiketals.

The structures of both these heptacyclic hemiketals $\mathbf{1 2}$ and $\mathbf{1 3}$ have been confirmed by ${ }^{1} \mathrm{H}$ and ${ }^{13} \mathrm{C}$ NMR spectral data and further supported by HRMS data. Finally their structures have been unambiguousily established by single crystal X-ray diffraction studies [48] (Figure 3).

Since our goal was to synthesize the diallylated compound 11, we screened various reaction conditions and finally, we found that the addition of the etheral solution of the hexacyclic dione

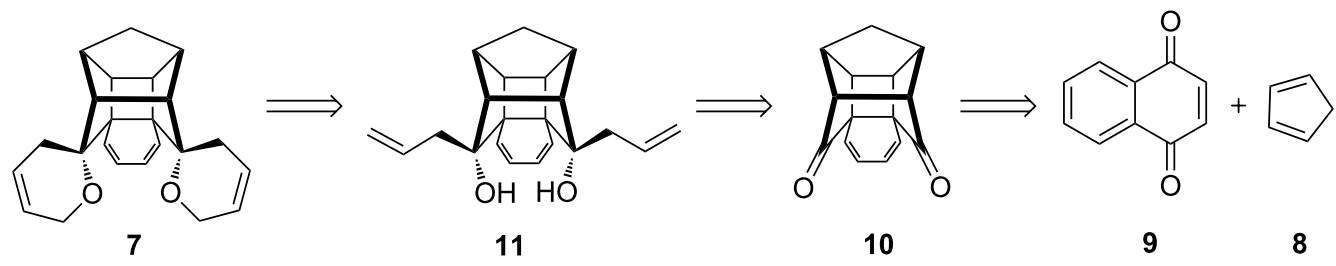

Figure 2: Retrosynthetic analysis of bis-spiro-pyrano cage compound 7. 


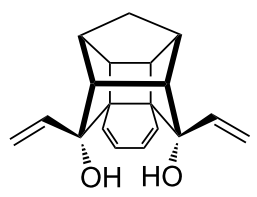

14 expected

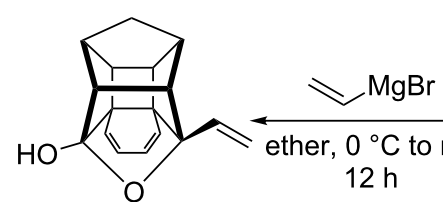

$13(89.2 \%)$

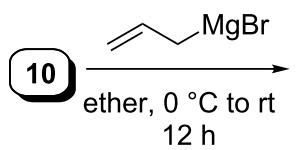

$12 \mathrm{~h}$

$$
12 \mathrm{~h}
$$

Scheme 2: Synthesis of tetrahydrofuran-based cage compounds 12 and 13.

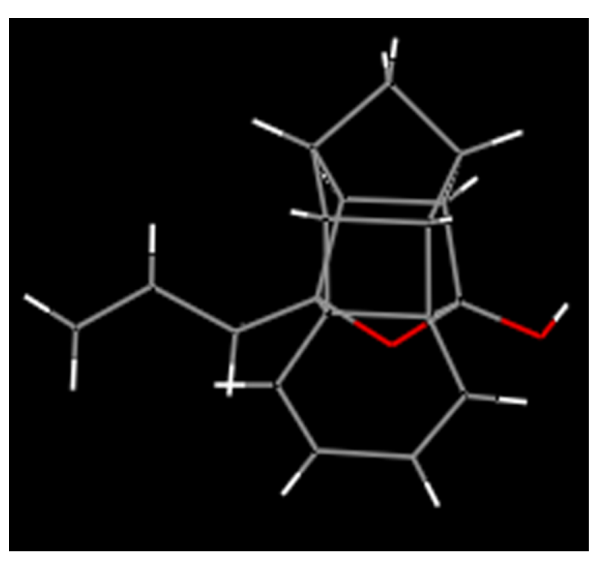

(a)

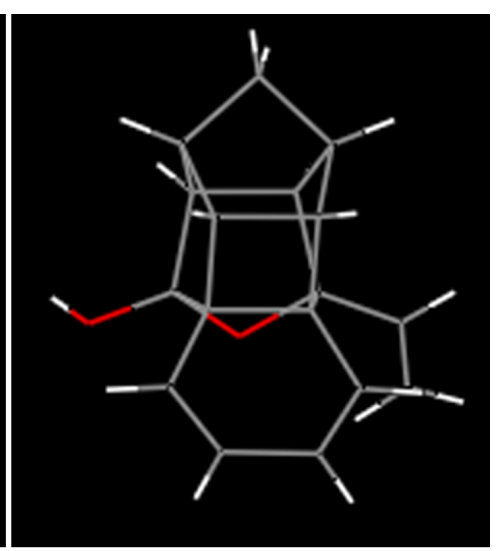

(b)

Figure 3: (a)Optimized structure of 12, (b) optimized structure of 13.

10 to a freshly prepared allyl Grignard reagent at $0{ }^{\circ} \mathrm{C}$ gave the expected diallylated compound 11 in 88\% yield (Scheme 3). The Grignard reagent at higher concentration (1.0 M solution) exists as a mixture of dimer, trimer and polymeric components. However, the home-made Grignard reagent at low concentration ( $0.1 \mathrm{M}$ solution) exists mostly in the monomeric form. So, we speculate that the difference in the concentration may be responsible for the formation of diol 11 [49-51]. Alternatively, when the diketone was reacted with an excess amount of Grignard reagent, the carbonyl groups are attacked simultaneously by the Grignard reagent and resulted in the formation of diol 11. When an excess amount of substrate containing carbonyl group was reacted with a limited amount of Grignard reagent, the oxyanion formed by the Grignard reagent attacks the other car- bonyl group in a transannular fashion to generate hemiketal derivatives $\mathbf{1 2}$ and $\mathbf{1 3 .}$

Later, the diallyldiol 11 was subjected to an $O$-allylation sequence under $\mathrm{NaH} / \mathrm{allyl}$ bromide conditions in $\mathrm{DMF}$ to deliver the desired tetraallyl compound 15 (53\%) along with the triallyl compound 16 (34.3\%) (Scheme 4). Subsequently, the tetraallyl compound $\mathbf{1 5}$ was subjected to an RCM sequence with the aid of Grubbs' first generation catalyst (G-I) in dry $\mathrm{CH}_{2} \mathrm{Cl}_{2}$. Surprisingly under these conditions the reaction was found to be sluggish.

Therefore, various other reaction conditions were screened to optimize the yields. Finally, we found that the Grubbs' first

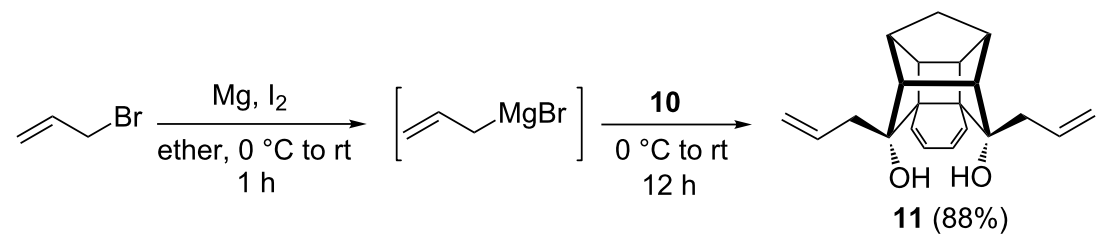

Scheme 3: Synthesis di-allyl cage compound 11. 


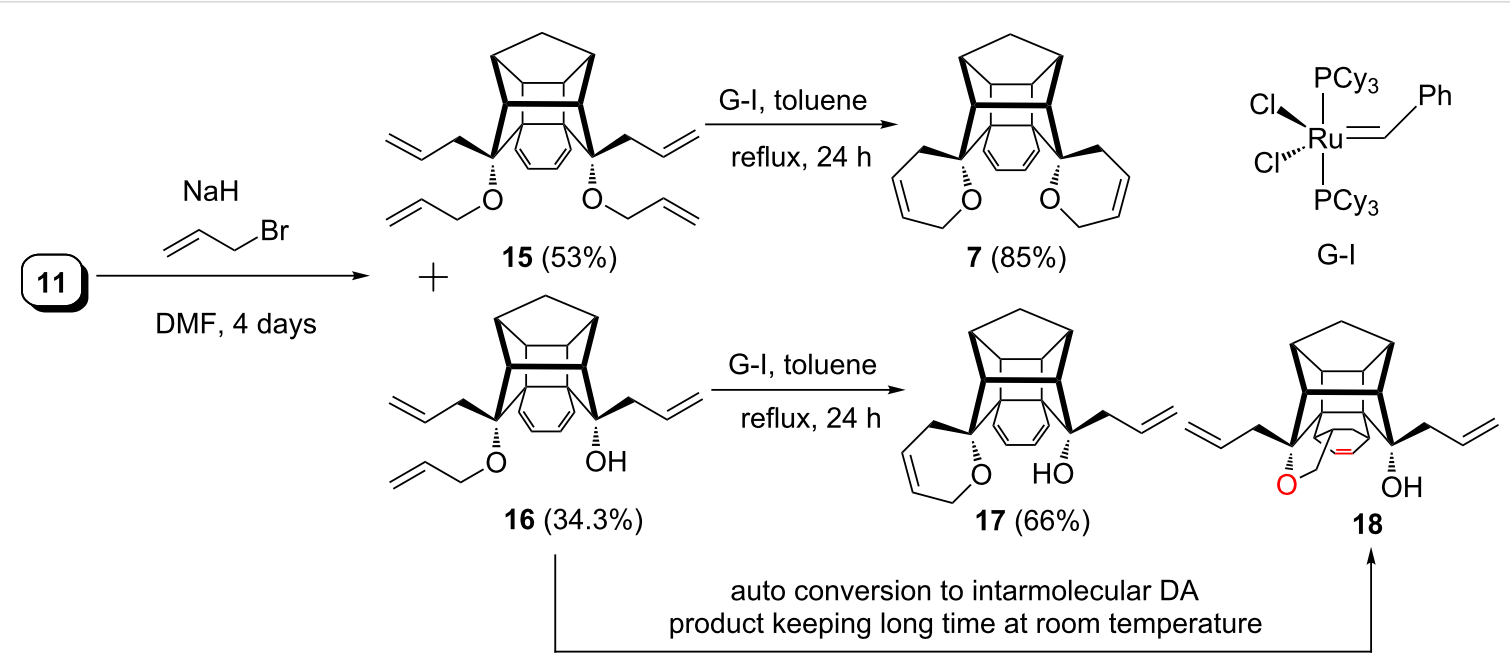

Scheme 4: Synthesis of spiro-pyrano cage molecules 7 and 17.

generation catalyst (G-I) in refluxing toluene gave the desired RCM product 7 in $85 \%$ yield. Along similar lines, the triallyl compound 16 gave the RCM product 17 in $66 \%$ yield (Scheme 4).

The structures of the annulated cage compounds $\mathbf{7}$ and $\mathbf{1 7}$ have been confirmed by ${ }^{1} \mathrm{H}$ and ${ }^{13} \mathrm{C}$ NMR spectral data and also supported by HRMS data with a molecular weight of 355.16 for 7 and 343.16 for compound 17, respectively. Furthermore, the structure of the bis-spiro pyrano cage compound 7 was confirmed by single crystal X-ray diffraction studies [52] (Figure 4). Fortunately, we observed that the liquid compound $\mathbf{1 6}$ kept at room temperature for a long time converted into a solid material. Therefore, we were keen to investigate the reason for this observation. In this context, the ${ }^{1} \mathrm{H}$ and
${ }^{13} \mathrm{C}$ NMR spectra of this compound were again recorded, indicating the occurence of an intramolecular DA reaction. Later, it was confirmed by single crystal X-ray diffraction studies [53] (Figure 4).

Next, the formation of compound $\mathbf{1 8}$ has been confirmed by an independent synthesis. To this end, triallyl compound $\mathbf{1 6}$ was subjected to intramolecular DA reaction in refluxing toluene to deliver the DA adduct $\mathbf{1 8}$ in 80\% yield (Scheme 5).

Surprisingly the related system 19, prepared from 12 did not undergo DA reaction to produce the intramolecular DA adduct 20. Even under prolonged toluene reflux reaction conditions, we did not realize the formation of the required DA product 20 (Scheme 6).

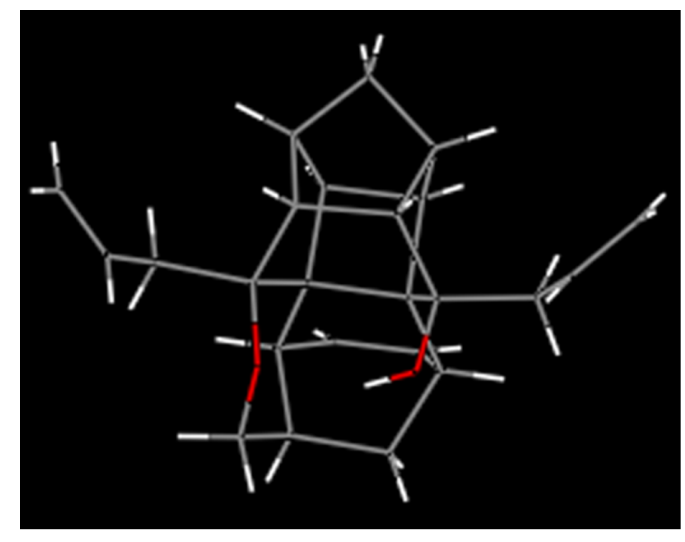

(a)

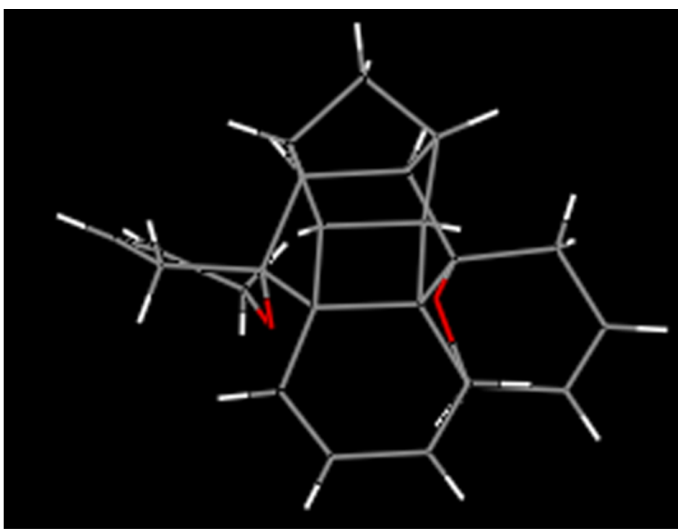

(b)

Figure 4: (a) Optimized structure of 18, (b) optimized structure of 7. 


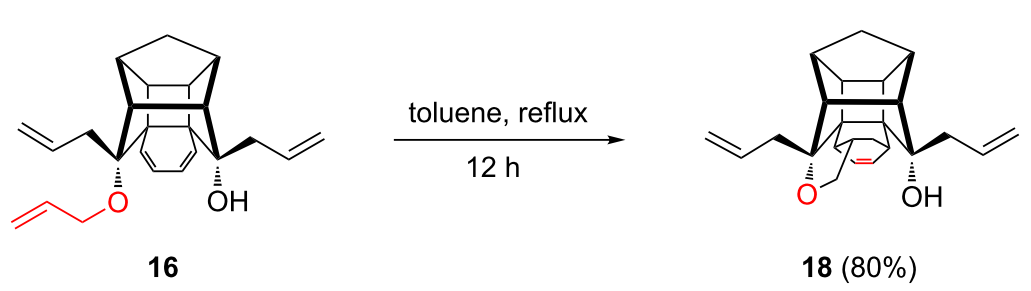

Scheme 5: Synthesis of octacyclic cage compound 18 via intramolecular DA reaction.

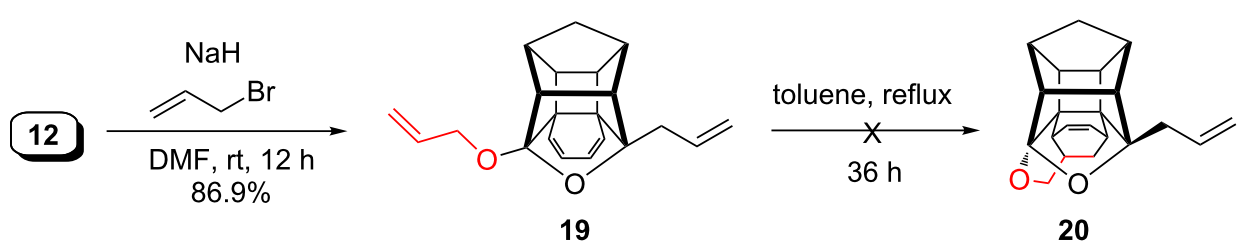

Scheme 6: Attempted synthesis to cage compound 20

\section{Conclusion}

In summary, we have demonstrated a new approach to intricate $C_{2}$-symmetric cage bis-spirocyclic pyran derivative 7 through an allyl Grignard reaction and an RCM sequence. The strategy demonstrated here involves an atom economic process. The synthetic sequence demonstrated here opens up a new route to complex cage targets. Additionally, intramolecular DA reaction opens up a new strategy for the synthesis of highly complex cage compounds that are inaccessible by other routes. Studies to extend the scope of the intramolecular as well as intermolecular DA reaction for the synthesis of interesting cage molecules are in progress.

\section{Supporting Information}

\section{Supporting Information File 1}

Detailed experimental procedures, characterization data and copies of ${ }^{1} \mathrm{H}$ and ${ }^{13} \mathrm{C}$ NMR spectra for all new compounds. [http://www.beilstein-journals.org/bjoc/content/ supplementary/1860-5397-11-147-S1.pdf]

\section{Acknowledgements}

We thank the Department of Science and Technology (DST), New Delhi for the financial support and the Sophisticated Analytical Instrument Facility (SAIF), IIT-Bombay for recording spectral data. S.K. thanks the Department of Science and Technology for the award of a J. C. Bose fellowship. M.S. thanks IIT-Bombay for the Istitute post-doc fellowship. R.A thanks the University Grants Commission (UGC), New Delhi and G.S thanks CSIR, New Delhi for the award of a research fellowship.

\section{References}

1. Marchand, A. P. Aldrichimica Acta 1995, 28, 95.

2. Marchand, A. P. In Advances in Theoretically Interesting Molecules; Thumel, R. P., Ed.; JAl: Greenwich, CT, 1989; Vol. 1, pp 357 ff.

3. Mehta, G.; Srikrishna, A. Chem. Rev. 1997, 97, 671. doi:10.1021/cr9403650

4. D'yakonov, V. A.; Trapeznikova, O. A.; de Meijere, A.; Dzhemilev, U. M. Chem. Rev. 2014, 114, 5775. doi:10.1021/cr400291c

5. Chamot, E.; Paquette, L. A. J. Org. Chem. 1978, 43, 4527. doi:10.1021/jo00417a031

6. Eaton, P. E.; Cassar, L.; Halpern, J. J. Am. Chem. Soc. 1970, 92, 6366. doi:10.1021/ja00724a061

7. Maier, G.; Pfriem, S.; Schäfer, U.; Matusch, R. Angew. Chem., Int. Ed. Engl. 1978, 17, 520. doi:10.1002/anie.197805201

8. Katz, T. J.; Acton, N. J. Am. Chem. Soc. 1973, 95, 2738 doi:10.1021/ja00789a084

9. Eaton, P. E.; Cole, T. W. J. Am. Chem. Soc. 1964, 86, 962. doi:10.1021/ja01059a072

10. McKennis, J. S.; Brener, L. J.; Ward, J. S.; Pettit, R. J. Am. Chem. Soc. 1971, 93, 4957. doi:10.1021/ja00748a076

11. Ternansky, R. J.; Balogh, D. W.; Paquette, L. A. J. Am. Chem. Soc. 1982, 104, 4503. doi:10.1021/ja00380a040

12. Carreño, M. C.; Garcia Ruano, J. L.; Urbano, A.; López-Solera, M. I. J. Org. Chem. 1997, 62, 976. doi:10.1021/jo9618942

13. Nair, M. S.; Sudhir, U.; Joly, S.; Rath, N. P. Tetrahedron 1999, 55 , 7653. doi:10.1016/S0040-4020(99)00381-6

14. Pandey, B.; Saravanan, K.; Rao, A. T.; Nagamani, D.; Kumar, P. Tetrahedron Lett. 1995, 36, 1145. doi:10.1016/0040-4039(94)02442-E

15. Chou, T.-C.; Lin, G.-H.; Yeh, Y.-L.; Lin, K.-J. J. Chin. Chem. Soc. 1997, 44, 477. doi:10.1002/jccs.199700073

16. Griesbeck, A. G. Tetrahedron Lett. 1988, 29, 3477. doi:10.1016/0040-4039(88)85194-3

17. Griesbeck, A. G.; Deufel, T.; Hohlneicher, G.; Rebentisch, R.; Steinwascher, J. Eur. J. Org. Chem. 1998, 1759. doi:10.1002/(SICI)1099-0690(199809)1998:9<1759::AID-EJOC1759>3 .0.CO;2-I 
18. Govender, T.; Hariprakasha, H. K.; Kruger, H. G.; Marchand, A. P. Tetrahedron: Asymmetry 2003, 14, 1553.

doi:10.1016/S0957-4166(03)00272-6

19. Paquette, L. A.; Ternansky, R. J.; Balogh, D. W.; Kentgen, G. J. Am. Chem. Soc. 1983, 105, 5446. doi:10.1021/ja00354a043

20. Marchand, A. P.; Kumar, K. A.; McKim, A. S.; Mlinarié-Majerski, K.; Kragol, G. Tetrahedron 1997, 53, 3467. doi:10.1016/S0040-4020(97)00075-6

21. Kotha, S.; Dipak, M. K. Beilstein J. Org. Chem. 2014, 10, 2664 doi:10.3762/bjoc. 10.280

22. Suwalsky, M.; jemiola-Rzeminska, M.; Altamirano, M.; Villena, F.; Dukes, N.; Strzalka, K. Biophys. Chem. 2015, 202, 13. doi:10.1016/j.bpc.2015.04.002

23. Kotha, S.; Seema, V.; Singh, K.; Deodhar, K. D. Tetrahedron Lett. 2010, 51, 2301. doi:10.1016/j.tetlet.2010.02.131

24. Paquette, L. A.; Beckley, R. S. J. Am. Chem. Soc. 1975, 97, 1084. doi:10.1021/ja00838a023

25. Abdelkafi, H.; Herson, P.; Nay, B. Org. Lett. 2012, 14, 1270. doi:10.1021/ol300133x

26. Ng, S. M.; Beaudry, C. M.; Trauner, D. Org. Lett. 2003, 5, 1701. doi:10.1021/ol0343414

27. Gupta, S.; Choudhury, R.; Krois, D.; Wagner, G.; Brinker, U. H.; Ramamurthy, V. Org. Lett. 2011, 13, 6074. doi:10.1021/ol202568s

28. Eey, S. T.-C.; Lear, M. J. Org. Lett. 2010, 12, 5510. doi:10.1021/ol102390t

29. Schneider, T. F.; Werz, D. B. Org. Lett. 2010, 12, 772. doi:10.1021/ol902904z

30. Kotha, S.; Dipak, M. K. Chem. - Eur. J. 2006, 12, 4446. doi:10.1002/chem.200501366

31. Vasquez, T. E., Jr.; Bergset, J. M.; Fierman, M. B.; Nelson, A.; Roth, J.; Khan, S. I.; O'Leary, D. J. J. Am. Chem. Soc. 2002, 124, 2931. doi:10.1021/ja016879f

32. Kruger, H. G.; Ramdhani, R. Magn. Reson. Chem. 2006, 44, 1058. doi:10.1002/mrc. 1889

33. Anderson, C. E.; Pickrell, A. J.; Sperry, S. L.; Vasquez, T. E., Jr.; Custer, T. G.; Fierman, M. B.; Lazar, D. C.; Brown, Z. W.; Iskenderian, W. S.; Hickstein, D. D.; O'Leary, D. J. Heterocycles 2007, 72, 469. doi:10.3987/COM-06-S(K)40

34. Osawa, E.; Yonemitsu, O. Carbocyclic Caged Compounds: Chemistry and Applications; Wiley: New York, 1992.

35. Mehta, G.; Srikrishna, A.; Reeddy, A. V.; Nair, M. S. Tetrahedron 1981, 37, 4543. doi:10.1016/0040-4020(81)80021-X

36. Marchand, A. P. Chem. Rev. 1989, 89, 1011. doi:10.1021/cr00095a004

37. Kotha, S.; Chakraborty, K. Indian J. Chem., Sect. B 2000, 39, 382.

38. Sasaki, T.; Eguchi, S.; Kiriyama, T.; Hiroaki, O. Tetrahedron 1974, 30 , 2707. doi:10.1016/S0040-4020(01)97433-2

39. Cookson, R. C.; Crundwell, E.; Hill, R. R.; Hudec, J. J. Chem. Soc. 1964, 3062. doi:10.1039/JR9640003062

40. Kushner, A. S. Tetrahedron Lett. 1971, 35, 3275. doi:10.1016/S0040-4039(01)97154-0

41. Valiulin, R. A.; Arisco, T. M.; Kutateladze, A. G. J. Org. Chem. 2011, 76, 1319. doi:10.1021/jo102221q

42. Kotha, S.; Chavan, A. S.; Goyal, D. ACS Comb. Sci. 2015, 17, 253. doi: $10.1021 / \cos 00146 u$

43. Suresh, R.; Muthusubramanian, S.; Senthilkumaran, R.; Manickam, G. J. Org. Chem. 2012, 77, 1468. doi:10.1021/jo202256z

44. Bhuyan, D.; Sarma, R.; Dommaraju, Y.; Prajapati, D. Green Chem. 2014, 16, 1158. doi:10.1039/c3gc42389a

45. Trost, B. M. Angew. Chem., Int. Ed. Engl. 1995, 34, 259. doi:10.1002/anie.199502591
46. Bott, S. G.; Marchand, A. P.; Kumar, K. A. J. Chem. Crystallogr. 1996, 26, 429. doi:10.1007/BF01665824

47. Bott, S. G.; Marchand, A. P.; Alihodzic, S.; Kumar, K. A. J. Chem. Crystallogr. 1998, 28, 251. doi:10.1023/A:1021893001351

48. CCDC 1053504 (12) and CCDC 1053505 (13) contain the supplementary crystallographic data for this paper. These data can be obtained free of charge from The Cambridge Crystallographic Data Centre via http://www.ccdc.cam.ac.uk/data_request/cif. (Hydrogen atoms are removed for better visualization).

49. Smith, M. B. Advanced Organic Chemistry: Reaction, Mechanism, Structure; Wiley: New York, 2013; p 231.

50. Ashby, E. C.; Smith, M. B. J. Am. Chem. Soc. 1964, 86, 4363. doi:10.1021/ja01074a026

51. Benn, R.; Lehmkuhl, H.; Mehler, K.; Rufińska, A. Angew. Chem., Int. Ed. Engl. 1984, 23, 534. doi:10.1002/anie.198405341

52. CCDC 1053506 (7) contain the supplementary crystallographic data for this paper. The data can be obtained free of charge from The Cambridge Crystallographic Data Centre via http://www.ccdc.cam.ac.uk/data_request/cif. (Hydrogen atoms are removed for better visualization).

53. CCDC 1053507 (18) contain the supplementary crystallographic data for this paper. The data can be obtained free of charge from The Cambridge Crystallographic Data Centre via http://www.ccdc.cam.ac.uk/data_request/cif. (Hydrogen atoms are removed for better visualization).

\section{License and Terms}

This is an Open Access article under the terms of the Creative Commons Attribution License (http://creativecommons.org/licenses/by/2.0), which permits unrestricted use, distribution, and reproduction in any medium, provided the original work is properly cited.

The license is subject to the Beilstein Journal of Organic Chemistry terms and conditions:

(http://www.beilstein-journals.org/bjoc)

The definitive version of this article is the electronic one which can be found at: $\underline{\text { doi: } 10.3762 / \text { bjoc. } 11.147}$ 